\title{
URBAN-RURAL AIR HUMIDITY DIFFERENCES IN SZEGED, HUNGARY
}

\author{
JÁNOS UNGER* \\ Department of Climatology and Landscape Ecology, József Attila University, P.O. Box 653, 6701, Szeged, Hungary \\ Received 8 September 1998 \\ Revised 23 March 1999 \\ Accepted 9 May 1999
}

\begin{abstract}
Measurements of vapour pressure, taken four times a day over a 3-year period, were used to investigate the urban influence on diurnal and annual patterns of vapour pressure differences. The examined settlement is a medium-sized city without significant relief in the Great Hungarian Plain. Its regional climate is continental with a long warm season. On the basis of the results, the air in the city centre is more humid than in the rural area both by day and at night for the duration of the whole year. The diurnal pattern shows that the urban excess has its minimum at 01:00 $\mathrm{h}$ and its maximum at 19:00 $\mathrm{h}$ in the summer months, but similar regular diurnal variation does not exist during the rest of the year. The annual patterns show that the excess increases from January-February to August and then decreases until November-December at each observation time. The differences and variations of urban humidity excess can be explained by different moisture sources and by different energy balances in the urban and rural environments. Unambiguous relationships exist between the variations of urban humidity excess and a regional aridity index, between the variations of humidity excess and the water temperature of the River Tisza crossing the city, as well as between the variations of humidity excess and maximum heat island intensity. The role of combustion processes is also significant, especially in the colder half of the year. Copyright (C) 1999 Royal Meteorological Society.
\end{abstract}

KEY WORDS: Szeged; Hungary; urban-rural humidity variations; vapour pressure

\section{INTRODUCTION}

The urban atmosphere is modified by the mainly artificial surface of the city, anthropogenic heat emission and air pollution in gaseous and aerosol phases. The effect of urbanization on the local climate has been investigated at an ever increasing rate throughout the world, but especially in mid-latitude cities. The effect of cities on air temperature (urban heat island) is now well documented for several cases (e.g. Oke, 1995; Kuttler, 1998), but only few studies have been written about the urban influence on atmospheric humidity. Among these studies only a few have made effective comparisons between urban and rural vapour pressure values (e.g. Kratzer, 1956; Lee, 1991). Efforts have concentrated mainly on relative humidity characteristics (e.g. Landsberg, 1981; Kuttler, 1998). Relative humidity values might be useful in human comfort studies, but they are not of great value in climate process work, because they are highly controlled by temperature values.

In this light, this paper concerns itself with the characteristics of some aspects of atmospheric vapour content in the city with the help of vapour pressure values.

The results of earlier investigations related to air humidity can be distinguished according to the location of the cities (mid-low latitude) and to the length of the data series (days, months and years). Some examples are discussed below, firstly in the case of mid-latitude settlements with short data series. In Leicester (England) and in Chapel Hill (N. Carolina) surface traverse relative humidity and dew point measurements have been made respectively (Chandler, 1967; Kopec, 1973). The cities have been found to

\footnotetext{
* Correspondence to: Department of Climatology and Landscape Ecology, József Attila University, P.O. Box 653, 6701 Szeged, Hungary.
}

CCC 0899-8418/99/131509-07\$17.50

Copyright (C) 1999 Royal Meteorological Society 
be moist at night and dry by day relative to their surroundings in autumn. Using long data series of absolute humidity in Edmonton (Alberta) and vapour pressure in London (England), Hage (1975) and Lee (1991), revealed that city values were lower by day but higher at night than the values in the country in summer. In winter they were higher in the city at all hours. In Chicago (Illinois) the urban-rural vapour pressure and dew-point differences were positive at night and negative in the forenoon and in summer afternoon (Ackerman, 1987). Secondly, in the case of low-latitude settlements, using long data series, in Ibadan (Nigeria), Adebayo (1991) found that the absolute humidity was higher in the city during the wet season and lower during the dry season. In Mexico City (Mexico) the specific humidity was higher in the city than in the nearby country during the wet season and at night. On the other hand, during the afternoon the reverse was true. These contrasts were smaller or insignificant during the dry season (Jáuregui and Tejeda, 1997).

\section{STUDY AREA}

Szeged is situated in the southeastern part of Hungary (Great Hungarian Plain). Its area is flat and low (79 m.a.s.1.); thus its climate is free from orographic effects (Figure 1). In the investigated period (1 January 1978-31 December 1980) the number of inhabitants of the city was up to 180000 and the surface of its built-up area was about $46 \mathrm{~km}^{2}$.

Most of the territory of Hungary (including the Szeged area) is in Köppen's climatic region $C f$ (temperate warm climate with uniform annual distribution of precipitation) or in the climatic region $D 1$ according to Trewartha's classification (continental climate with a long warm season). In addition, the regional climate of Szeged has a particular Mediterranean influence, namely in every 10 years approximately 3 years show Mediterranean character in the annual variation of precipitation (Koppány and Unger, 1992).

A detailed climatic partitioning of Hungary may be made using the mean temperature of vegetative growth season $\left(t_{\mathrm{vs}}\right.$ in ${ }^{\circ} \mathrm{C}$ ) and the aridity index $H=Q^{*} / L_{v} P$ (where $Q^{*}$ is the annual mean net radiation in $\mathrm{MJ} \mathrm{m}{ }^{-2}, L_{v}$ is the latent heat of vapourization in $\mathrm{MJ} \mathrm{kg} \mathrm{kg}^{-1}$ and $P$ is the annual mean precipitation in $\mathrm{kg} \mathrm{m}^{-2}$ ). The index $H$ is dimensionless. If $H>1$, the climate is arid and if $H<1$, the climate is humid. Szeged is in the warm-dry climatic region according to this classification which is characterized by $t_{\mathrm{vs}}>17.5^{\circ} \mathrm{C}$ and $H>1.15$ (Péczely, 1979).

\section{DATA AND METHODS}

In the urban area of Szeged a network with 10 climatological stations was established in the late 1970s and observations were taken in the period between 1978 and 1980. The stations represented different neighbourhoods of the city, namely the densely built-up city core with medium narrow streets, the housing estates which contain tall concrete buildings with rather wide green areas, the other zones with detached houses, the banks of River Tisza, the large parks and the almost natural outskirts. Among them, the urban influence was concentrated on the measurement site in the city centre because of its central location (and building density) and the distance from the city edge. By contrast, the station in the outskirts was influenced least of all. As our aim is to compare the typical and the most distinguished urban and rural humidity patterns in Szeged, in this study only the time series of these two selected stations were examined (Figure 1).

The stations represent rural and inner city conditions, respectively. To show the immediate surroundings of the measurement sites we depict the surface and built-up features there. For the characterization of the nearby area, a circle with the radius of $0.5-1 \mathrm{~km}$ is appropriate (Oke et al., 1992). In our case the circles with the radius of $0.6 \mathrm{~km}$ are most appropriate for the size of Szeged (the dimensions of the city are 10 and $8 \mathrm{~km}$ wide in the $\mathrm{E}-\mathrm{W}$ and $\mathrm{N}-\mathrm{S}$ directions, respectively). As Figure 1 shows, apart from the two small one-storey houses belonging to the meteorological station (a permanent station of the 


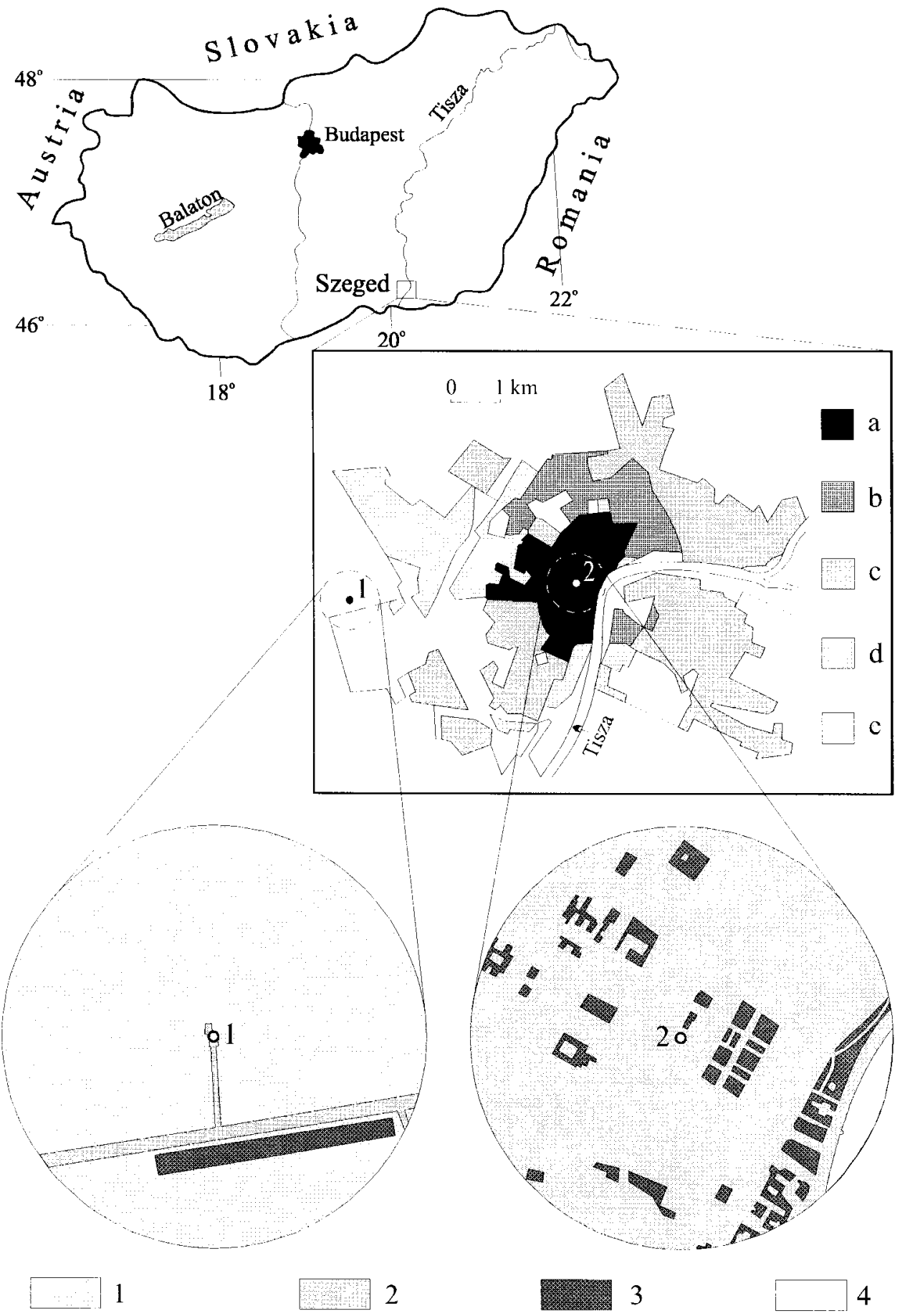

Figure 1. Location of Szeged in Hungary, sites of the urban (2) and rural (1) stations with their immediate (circle with $0.6 \mathrm{~km}$ radius) surroundings and built-up types of the city. (a) downtown (2-4 storey old buildings); (b) housing estates with pre-fabricated concrete slabs (5-10 storey buildings); (c) detached houses (1-2 storey buildings); (d) industrial areas; (e) green areas. (1) ploughed land; (2) paved surface (street, pavement, building); (3) green surface; (4) water surface 
Hungarian Meteorological Service), and the road surface, the area surrounding Station 1 is agricultural, consisting of mainly non-irrigated wheat and maize fields. It is situated at a distance of $4.4 \mathrm{~km}$ to the west of the city centre. The sky-view factor of the rural site is almost 1 . The temporary Station 2 was set up at a paved square bounded by multi-storey buildings in the city centre. Its vicinity is a densely built-up and paved area with mainly 3-4 storey buildings which are only occasionally interrupted by green (parks and river bank) and water (river) surfaces. The sky-view factor of the urban site is 0.54 .

Wet- and dry-bulb measurements were taken four times a day (at 01:00, 07:00, 13:00 and 19:00 h, Central European Time) by observers, and the values were written and stored in prepared tables on a monthly basis. Both stations had thermometer shelters with Assman-type psychrometers with an accuracy of $0.1^{\circ} \mathrm{C}$ at a height of $2 \mathrm{~m}$ above ground level. The calibration was controlled every month by comparing the instruments. The vapour pressure values were calculated with the help of the psychrometer table of the Hungarian Meteorological Service (OMSZ, 1982), which contains humidity values at temperatures between -40 and $+50^{\circ} \mathrm{C}$.

In the present analysis, a relatively simple method was applied, in which monthly mean values were determined for both stations and urban-rural differences of means were calculated at each observation time. Also an attempt is made to explain the sign and magnitudes of these differences.

\section{RESULTS AND DISCUSSION}

Table I clearly shows that the city has a vapour pressure excess during the whole year. This excess has a simple annual cycle with a minimum in winter (February) and a maximum in August, at each observation time.

In the diurnal course of the urban excess there is a minimum at 01:00 $\mathrm{h}$ and a maximum at 19:00 $\mathrm{h}$ in the summer months, but similar regular diurnal variation does not exist during the rest of the year.

The annual maximum values in August have a diurnal range of $2.2 \mathrm{hPa}$ (between 3.4 and $5.6 \mathrm{hPa}$ increasing from 01:00 to 19:00 h). The minimum values of the urban excess are in February and December $(0.7$ and $0.8 \mathrm{hPa})$. Thus, the annual variation of urban-rural humidity difference in Szeged is only partly similar to the results of other mid-latitude cities with long data series such as Edmonton (Hage, 1975), London (Lee, 1991) and Chicago (Ackerman, 1987), necessitating some explanation. Naturally, the deviation could be caused partly by the different city structures, the different extent of urbanization and the different regional climates within the temperate zone. As far as the regional climate is concerned, by Köppen; London is in the climatic region $C f$ (as Szeged), Edmonton and Chicago are in the $D f$ (cold winter, uniform annual distribution of precipitation). According to Trewartha's classification, London is in the climatic region $C 3$ (mild seaside climate), Edmonton is in the D2 (continental climate with a short warm season) and Chicago is in the D1 (as Szeged) (Péczely, 1979).

In order to explain the peculiarity of Szeged, further climatological and other factors have to be taken into account. These are the aridity index mentioned above (mean net radiation is calculated by Dobosi, 1973; mean precipitation is given by Péczely, 1979), the maximum urban heat island intensity (Unger, 1992) and the water temperature of River Tisza. The aridity index is calculated for the rural area;

Table I. Monthly mean vapour pressure excesses $(\mathrm{hPa})$ of the city at different observation times in Szeged

\begin{tabular}{cllllllllllll}
\hline & $\mathrm{J}$ & $\mathrm{F}$ & $\mathrm{M}$ & $\mathrm{A}$ & $\mathrm{M}$ & $\mathrm{J}$ & $\mathrm{J}$ & $\mathrm{A}$ & $\mathrm{S}$ & $\mathrm{O}$ & $\mathrm{N}$ & $\mathrm{D}$ \\
\hline 01:00 h & 1.0 & 0.7 & 1.4 & 2.0 & 2.3 & 2.6 & 3.0 & 3.4 & 2.9 & 2.4 & 0.8 & 1.4 \\
07:00 h & 0.9 & 0.7 & 1.5 & 1.6 & 1.7 & 2.9 & 3.0 & 3.6 & 2.0 & 2.2 & 0.8 & 1.0 \\
13:00 h & 1.2 & 0.8 & 2.3 & 2.2 & 2.5 & 3.9 & 4.2 & 4.8 & 3.1 & 2.3 & 2.2 & 1.1 \\
19:00 h & 1.0 & 0.9 & 1.9 & 2.1 & 3.5 & 4.6 & 5.0 & 5.6 & 3.0 & 2.8 & 0.8 & 0.7 \\
Daily mean & 1.0 & 0.8 & 1.8 & 2.0 & 2.5 & 3.5 & 3.8 & 4.3 & 2.7 & 2.4 & 1.1 & 1.0 \\
\hline
\end{tabular}




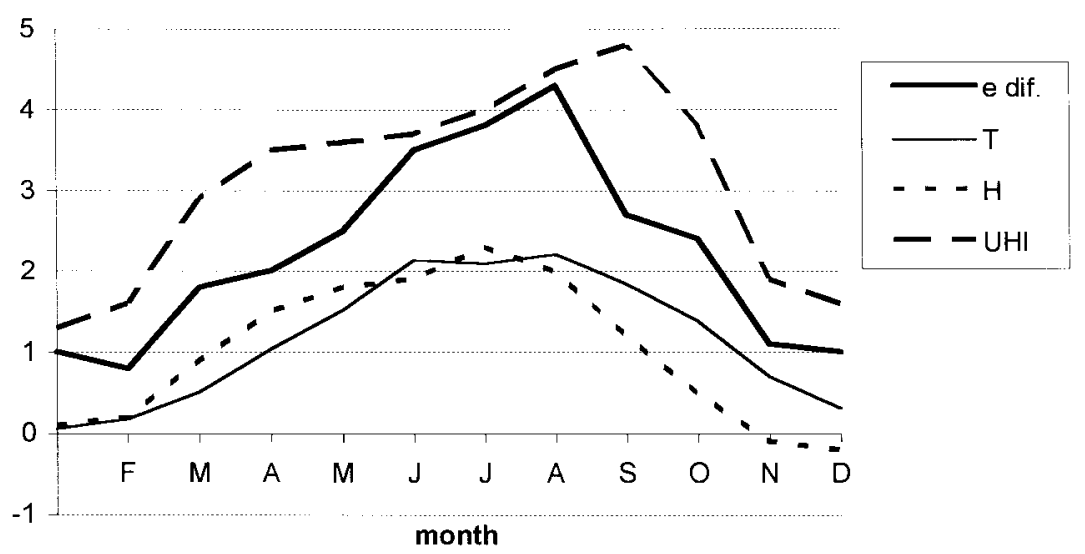

Figure 2. Annual variations of the monthly means of the daily vapour pressure excess of the city $(e-$ unit $1 \mathrm{hPa})$, the water temperature of River Tisza $\left(T\right.$ - unit $\left.10^{\circ} \mathrm{C}\right)$, the aridity index $(H$ - unit 1 , dimensionless $)$ and the maximum heat island intensity (UHI-unit $1^{\circ} \mathrm{C}$ ) in Szeged

therefore, it characterizes the general climate of the Szeged region. The heat island intensity values refer to the air temperature measured at the same sites (Station 1 and 2) and in the same period (1978-1980) as the vapour pressure values. The water temperature was measured two times per day (morning and afternoon) at the river curve near the city centre (Figure 1) at a depth of $30-40 \mathrm{~cm}$ at the mainstream of the river using a tank thermometer with an accuracy of $0.1^{\circ} \mathrm{C}$. The values are given in the year-books of the Hungarian Water Management Research Centre (VITUKI, 1978-1980). With the help of a diagram depicting these data we can get a clearer picture about the possible relationships (Figure 2):

(i) The examination of annual variation of the aridity index in the Szeged region shows that this drought-measure of the climate increases until July and it is also very high in August, since the precipitation as water input is much less than the potential evaporation determined by the net energy $\left(Q^{*}\right)$. This establishment is valid for Station 1 which represents the natural climate of the region.

(ii) In the case of Station 2 (urban) the evaporation of River Tisza can enhance the air humidity, because the distance between the station and the river is only $0.5 \mathrm{~km}$. In contrast, Station 1 (rural) is far (5.0 $\mathrm{km}$ ) from the evaporative surface of River Tisza. The water of the river is the warmest and also the moisture capacity of air is the greatest in the summer months (June-August). Thus, the water surface can add abundant moisture to the local air at this time. This time coincides well with the maximum of the urban humidity excess.

(iii) At the end of summer the evapotranspiration of the rural natural surface is very weak because of the harvest (in the first half of July) and the almost complete desiccation of the soil and the remaining agricultural and natural vegetation. On the other hand, parks and gardens in the city are irrigated in this period of the year. This guarantees freely transpiring vegetation and a higher rate of evapotranspiration in the city. This can also contribute to the late summer (August) maximum of urban-rural humidity difference and can compensate the slight decrease of the aridity index and the temperature of the river water at this time.

Therefore, on a seasonal basis, both the higher aridity index and the higher water temperature of River Tisza (with some time lag because of the heat inertia) contribute to the greater urban-rural vapour pressure difference in the warmer months. This combined effect is aided by the difference of the land surface evapotranspiration.

Nevertheless, there are some other factors which are likely to be involved in the development of urban humidity excess. They are probably less important but we should count them:

(I) The aridity index mentioned above refers to the natural climate of the Szeged region. However, the moisture capacity of urban air is higher than the rural one because of the higher urban temperature 
(urban heat island). The maximum heat island intensity is an appropriate measure of the increased urban temperature. In its annual variation there is also a late summer maximum similar to the variation of other measures mentioned previously. Therefore, the elevated urban temperature strengthens the effect of evapotranspiration on the vapour pressure difference, especially in the summer months.

(II) Water vapour released by combustion processes can also contribute to the development of an urban humidity excess. The vapour from gas heating and traffic in the city is trapped in the narrow streets of the city centre, so the vapour content of the air is higher there than in the better ventilated rural areas.

The effect of the last factor (II) may increase the air humidity content particularly in the colder half-year, the time when the roles of factors (i), (ii) and (iii) may decrease significantly.

\section{CONCLUSIONS}

The following conclusions can be reached on the basis of the analysis of the 3-year vapour pressure data series of rural and urban stations and other climatological data from the Szeged area. There is an urban vapour pressure excess during the whole year, with a summer maximum. For the purpose of this study, the comparison of results of Szeged is compatible with the results of some other, mid-latitude cities using data series of some of the years mentioned earlier (Edmonton, London and Chicago). In contrast to these cities, the urban vapour pressure in Szeged is higher than its rural counterpart at daytime in summer.

For an explanation of this deviation (between the previous results of the mentioned cities and our results), some possible reasons could be found, which are valid numerically or theoretically. Partly, these reasons might be the different city structures, the different extent of urbanization, partly the different regional climates within the temperate zone: the special climatological characteristics of the region of Szeged (they are represented by the aridity index), the additional evaporative surfaces in the city (River Tisza, irrigated green areas), the elevated urban temperature and the influence of urban combustion processes. We can suggest that the relative significance of these different factors is dependent on the seasonal variability. In summer, when the maximum of the urban humidity excess occurs, the higher rate of aridity index, the evaporative surfaces and the urban heat excess may play dominant roles. On the other hand, in winter the role of combustion processes (partly in connection with the low wind speed in this season) may be enhanced.

\section{ACKNOWLEDGEMENTS}

This study was supported by the grants of the Hungarian Scientific Research Fund (OTKA T/023042), the Hungarian Soros Foundation and the National Commission for Technical Development (OMFB). Special thanks are due to Professor T.R. Oke (Univ. British Columbia, Vancouver) for his suggestions in the preliminary stage of the manuscript and also to the anonymous referees.

\section{REFERENCES}

Ackerman, B. 1987. 'Climatology of Chicago area urban-rural differences in humidity', J. Cl. Appl. Met., 26, 427-430.

Adebayo, Y.R. 1991. 'Day-time effects of urbanization on relative humidity and vapour pressure in a tropical city', Theor. Appl. Climatol., 43, 17-30.

Chandler, T.J. 1967. 'Absolute and relative humidities in towns', Bull. Am. Met. Soc., 48, 394-399.

Dobosi, Z. 1973. Areal Distribution of the Energy-Balance in Hungary, (in Hungarian), Unpublished Doctoral Thesis, ELTE, Budapest, p. 138.

Hage, K.D. 1975. 'Urban-rural humidity differences', J. Appl. Met., 14, 1277-1283.

Jáuregui, E. and Tejeda, A. 1997. 'Urban-rural humidity contrasts in Mexico City', Int. J. Climatol., 17, $187-196$.

Kopec, R.J. 1973. 'Daily spatial and secular variations of atmospheric humidity in a small city', J. Appl. Met., 12, 639-648.

Koppány, G. and Unger, J. 1992. 'Mediterranean climatic character in the annual march of precipitation', Acta Climatol. Univ. Szeged., 24-26, 59-71. 
Kratzer, A. 1956. Das Stadtklima, Wieweg and Sohn, Braunschweig, p. 184.

Kuttler, W. 1998. 'Stadtklima', in Heyer, E. (ed.), Witterung und Klima, Teubner, Stuttgart-Leipzig, pp. 328-364.

Landsberg, H.E. 1981. The Urban Climate, Academic Press, New York, p. 275.

Lee, D.O. 1991. 'Urban-rural humidity differences in London', Int. J. Climatol., 11, 577-582.

Oke, T.R. 1995. 'The heat island of the urban boundary layer: Characteristics, causes and effects', in Cermak, J.E. et al. (eds.), Wind Climate in Cities, Kluwier Academic Publishers, pp. 81-107.

Oke, T.R. et al. 1992. 'The surface energy balance in Mexico City', Atm. Environ., 26B, 433-444.

Péczely, Gy. 1979. Climatology (in Hungarian), Tankönyvkiadó, Budapest, p. 336.

Unger, J. 1992. 'Diurnal and annual variation of the urban temperature surplus in Szeged, Hungary', Idõjárás, 96, $235-244$.

VITUKI, 1978-1980. Year-books of the Hungarian Water Management Research Centre (VITUKI), Budapest.

OMSZ, 1982. Tables for the calculation of the values of aspirated psychrometers. Hungarian Meteorological Service, Budapest. 